\title{
Prevalensi Sarkopenia pada Lansia di Komunitas (Community Dwelling) berdasarkan Dua Nilai Cut-off Parameter Diagnosis
}

\author{
Vitriana, ${ }^{1}$ Irma Ruslina Defi, ${ }^{1}$ Gaga Irwan Nugraha, ${ }^{2}$ Budi Setiabudiawan ${ }^{3}$ \\ ${ }^{1}$ Departemen Ilmu Kedokteran Fisik dan Rehabilitasi Fakultas Kedokteran Universitas Padjadjaran/Rumah Sakit \\ Dr. Hasan Sadikin Bandung, ${ }^{2}$ Departemen Ilmu Gizi Fakultas Kedokteran Universitas Padjadjaran/Rumah Sakit \\ Dr. Hasan Sadikin Bandung, ${ }^{3}$ Departemen Ilmu Kesehatan Anak Fakultas Kedokteran Universitas Padjadjaran/ \\ Rumah Sakit Dr. Hasan Sadikin Bandung
}

\begin{abstract}
Abstrak
Sarkopenia, sindrom penurunan massa dan fungsi otot terkait usia dapat mengurangi kualitas hidup dan peningkatan mortalitas pada lanjut usia (lansia). Banyak metode penapisan dan definisi operasional menyebabkan angka prevalensi sarkopenia bervariasi di dunia. Penelitian ini bertujuan mengetahui prevalensi sarkopenia pada lansia yang tinggal di komunitas berdasarkan massa otot yang diukur dengan bioimpedance analysis, kekuatan genggam tangan menggunakan hand dynamometer, serta performa fisik melalui uji jalan 6 menit dengan mempergunakan dua nilai cut-off, nilai rekomendasi Asian Working Group for Sarcopenia (AWGS) dan nilai populasi lansia Taiwan karena belum didapatkan nilai cut-off populasi lansia Indonesia. Penelitian deskriptif potong lintang pada 229 partisipan (71 orang laki-laki dan 158 orang perempuan) dengan menggunakan teknik consecutive sampling dilakukan pada bulan Agustus sampai Desember 2014 pada populasi lansia di Kota Bandung dan Jatinangor. Hasil penelitian menunjukkan angka prevalensi sarkopenia berdasarkan nilai cut-off rekomendasi AWGS adalah 9,1\% (7,4\% untuk laki-laki dan 1,7\% untuk perempuan), sedangkan prevalensi sarkopenia berdasarkan nilai cut-off populasi Taiwan sebesar 40,6\% (20,1\% untuk laki-laki dan 20,5\% untuk perempuan). Perbedaan prevalensi yang cukup besar mendorong diperlukan penetapan nilai cut-off parameter diagnosis sarkopenia spesifik pada populasi lansia Indonesia yang tinggal di komunitas untuk dapat menentukan prevalensi sarkopenia lebih akurat. [MKB. 2016;48(3):164-70]
\end{abstract}

Kata kunci: Cut-off, lansia, komunitas, prevalensi, sarkopenia

\section{Sarcopenia Prevalence In Community-Dwelling Elderly based on Two Cut-off Points Diagnosis Parameters}

\begin{abstract}
Sarcopenia, aging muscle mass loss, and function syndromes can lead to decreased quality of life and increased elderly mortality. The availability of various screening methods and operational definitions in different studies has produced different findings of sarcopenia prevalence. The purpose of this study was to discover the prevalence of sarcopenia in Indonesian community-dwelling elderly based on muscle mass measured by bioimpedance analysis, handgrip strength using hand dynamometer, and physical performance based on six minutes walking test with two different cut-off point parameters of sarcopenia, i.e. the cut-off point recommended by Asian Working Group for Sarcopenia (AWGS) and the cut-off point based on the reference used in Taiwan elderly population reference due to the lack of references for Indonesian elderly population. A cross-sectional study was conducted to 229 participants (71 men and 158 women) from the community-dwelling elderly population between August and December 2014 in Bandung and Jatinangor. The results of the study showed that the sarcopenia prevalence in this study based on AWGS was 9.1\% (7.4\% in men and 1.7\% in women) while the prevalence based on the Taiwan reference revealed a prevalence of $40.6 \%$ (20.1\% in men and $20.5 \%$ in women). This highly different prevalences shows the importance of defining a specific cut-off point for elderly population in community-dwelling Indonesia to get a more accurate sarcopenia prevalence. [MKB. 2016;48(3):164-70]
\end{abstract}

Key words: Community dwelling, cut-off, elderly, prevalence, sarcopenia

Korespondensi: Vitriana, dr., Sp.KFR, Departemen Ilmu Kedokteran Fisik dan Rehabilitasi Fakultas Kedokteran Universitas Padjadjaran/Rumah Sakit Dr. Hasan Sadikin Bandung, Jalan Pasteur No. 38 Bandung, mobile 08156262733, e-mail vitriana02@ gmail.com 


\section{Pendahuluan}

Penuaan berdampak pada perubahan struktur tubuh, yaitu seperti hilangnya secara progresif massa otot, perlambatan pergerakan otot, dan juga penurunan kekuatan otot. ${ }^{1}$ Fenomena ini diperkenalkan oleh Rosenberg pada tahun 1989 sebagai sarkopenia (Yunani) yang merupakan singkatan dari "sarco-" atau otot dan "-penia" yang mengindikasikan defisiensi otot. ${ }^{2}$ Definisi terbaru kemudian dipublikasikan oleh European Working Group on Sarcopenia in Older People (EWGSOP) pada tahun 2010 yang memasukkan perubahan fungsi otot atau kelemahan otot yang menyertai berkurangnya massa otot. ${ }^{2,3}$ Sarkopenia telah dilaporkan berhubungan secara bermakna dengan impairment fungsional dan disabilitas pada lanjut usia (lansia) yang akan berdampak pada kualitas hidup dan selanjutnya kemampuan bertahan hidup sehingga menjadi hal yang penting untuk diperhatikan agar dapat dilakukan langkah-langkah pencegahan dan antisipasif ${ }^{1,2,4}$

Tidak ada konsensus definisi sarkopenia dan bervariasinya kriteria diagnostik (nilai normatif untuk cut-off point parameter sarkopenia) menyebabkan prevalensi sarkopenia bervariasi pada berbagai macam penelitian kohor dengan rentang 7-50\% pada lansia. ${ }^{5}$ Pada tahun 2009 EWGSOP mempublikasikan definisi klinis dan kriteria diagnostik untuk penegakan diagnosis sarkopenia yang didasarkan pada massa otot dan fungsi otot (kekuatan dan atau performa fisik) yang rendah. ${ }^{3}$ Asian Working Group for Sarcopenia (AWGS) kemudian melakukan suatu pendekatan yang sama dengan EWGSOP dan merekomendasikan nilai cut-off parameterparameter diagnosis sarkopenia yang berbeda dengan Eropa sebagai acuan penegakan diagnosis sarkopenia di populasi Asia. Perbedaan etnisitas, ukuran tubuh, gaya hidup, dan latar belakang budaya antara populasi Asia dan Kaukasia serta antarpopulasi Asia memunculkan hasil bervariasi untuk nilai cut-off ini antarpopulasi. ${ }^{6}$ Populasi lansia Taiwan dengan karakteristik antropometri yang menyerupai populasi lansia di Indonesia dengan usia harapan hidup yang lebih mendekati populasi lansia Indonesia yang mempunyai nilai cut-off yang berbeda pula dengan rekomendasi AWGS.?

Proporsi lansia di Indonesia yang meningkat jumlahnya seiring dengan peningkatan derajat kesehatan dan kesejahteraan penduduk di Indonesia telah memunculkan kecenderungan peningkatan sarkopenia. Sarkopenia tersebut dapat disebabkan oleh berbagai macam hal selain penuaan, seperti pengurangan aktivitas fisik, kelainan persarafan, abnormalitas metabolik, dan perubahan aktivasi sel-sel satelit. ${ }^{8}$ Perbedaan karakteristik populasi lansia di Indonesia dengan populasi lansia di negara lain adalah belum ada nilai normatif cut-off parameter-parameter diagnosis sarkopenia serta angka prevalensi sarkopenia untuk populasi lansia di komunitas (community dwelling) Indonesia.Penelitian ini berupaya memperlihatkan gambaran prevalensi sarkopenia pada populasi lansia Indonesia di komunitas dengan mempergunakan dua nilai normatif cut-off pada parameter diagnosis sarkopenia yang mengacu pada rekomendasi AWGS dan juga populasi Taiwan. Diharapkan hasil penelitian ini dapat menjadikan dasar pengembangan penelitian epidemiologi lebih lanjut serta strategi tatalaksana menyeluruh termasuk tindakan pencegahan sarkopenia.

\section{Metode}

Penelitian deskriptif potong lintang dilakukan pada lansia di komunitas Kota Bandung dan Jatinangor periode Agustus hingga Desember 2014. Partisipan berusia lebih dari 60 tahun (sesuai dengan definisi lansia menurut UndangUndang Republik Indonesia No. 13 Tahun 199, mampu berjalan di dalam dan di luar rumah secara mandiri tanpa alat bantu, tidak mempunyai gangguan kognisi [skor Mini-Mental State Examination (MMSE) $\geq 24$ ], tidak bertempat tinggal di institusi khusus lanjut usia, mampu menggenggam serta kooperatif. Partisipan ini dieksklusi dari penelitian apabila mengalami gangguan kardiorespirasi atau kardiovaskular berat sehingga tidak mampu menjalani uji penapisan diagnosis sarkopenia, menggunakan implan artifisial yang akan mengganggu akurasi pengukuran, sedang menjalani terapi atau sedang mengonsumsi obat-obatan yang memengaruhi kapasitas latihan, dan juga menderita penyakit yang dapat menyebabkan hilangnya massa otot. Luaran yang dinilai adalah parameter diagnosis sarkopenia yang terdiri atas penilaian massa otot, kekuatan otot, dan performa fisik berdasarkan nilai cut-off AWGS dan populasi Taiwan.

Pengambilan data tersebut dilakukan setelah mendapatkan persetujuan dari Komite Etik Penelitian Kesehatan (KEPK) Fakultas Kedokteran Universitas Padjadjaran. Semua partisipan diinformasikan tentang prosedur penelitian dan juga informed consent didapatkan sebelum penelitian dimulai dan menandatangani lembar persetujuan. Wawancara ini dilakukan 
Tabel 1 Nilai Cut-off untuk Parameter Diagnosis Sarkopenia

\begin{tabular}{lcccc}
\hline \multirow{2}{*}{ Parameter } & \multicolumn{2}{c}{ AWGS*1 } & \multicolumn{2}{c}{ Populasi Taiwan*2 } \\
\cline { 2 - 5 } & Laki-laki & Perempuan & Laki-laki & Perempuan \\
\hline Massa otot $\left(\mathrm{kg} / \mathrm{m}^{2}\right)$ & $<7,0$ & $<5,7$ & $<8,87$ & $<6,42$ \\
Kekuatan otot $(\mathrm{kg})$ & $<26$ & $<18$ & $<22,5$ & $<14,5$ \\
Performa fisik (m/detik) & & $\leq 0,8$ & & $\leq 1$ \\
\hline
\end{tabular}

Keterangan: ${ }^{* 1}$ Dikutip dari Chen dkk., ${ }^{62}$ Lin dkk., ${ }^{9}$ Chen dkk. ${ }^{11}$

untuk pengumpulan data yang sudah dilakukan oleh tim dan distandardisasi sebelumnya oleh peneliti. Data yang diperoleh kemudian dianalisis mempergunakan Stat Soft 4.5.

Penilaian massa otot memakai Bioelectrical impedance analysis (BIA) (Tanita BC-601, Tokyo, Jepang). Partisipan berdiri tanpa alas kaki pada papan analisis dan menggenggam alat pendeteksi dengan kedua tangan. Data untuk massa otot diambil dengan menghitung indeks massa otot melalui kalkulasi appendicular skeletal muscle mass (ASM) yang didapatkan dari total massa otot kedua tungkai bawah dan atas dalam kilogram dibagi dengan kuadrat tinggi badan dalam meter $\left(\mathrm{ASM} / \mathrm{TB}^{2}\right) .{ }^{9}$ Penilaian kekuatan otot menggunakan dinamometer tangan (Jamar, J00105, Lafayette Hand Dynamometer, Amerika) dalam satuan kilogram. Pengukuran dilakukan sebanyak tiga kali pada tangan dominan untuk kemudian diambil nilai tertinggi dalam posisi berdiri. ${ }^{9}$

Pengukuran performa fisik dilakukan dengan mengukur kecepatan berjalan dengan uji jalan 6 menit. Dilakukan perhitungan jarak tempuh yang mampu dilakukan oleh partisipan selama jangka waktu tersebut untuk menentukan kecepatan berjalan dalam meter per detik. Seluruh proses uji jalan 6 menit menggunakan prosedur sesuai dengan American Thoracic Society (ATS). ${ }^{10}$

Penelitian ini mempergunakan pendekatan algoritma yang sudah ditetapkan oleh AWGS mengacu pada EWGSOP untuk menegakkan diagnosis sarkopenia. Referensi untuknilai cut-off parameter sarkopenia diambil nilai cut-off yang disarankan oleh AWGS dan dari data normatif penelitian yang dilakukan pada populasi Taiwan sebelumnya sebagai perbandingan (Tabel 1). Algoritma penegakan diagnosis mengacu pada konsensus yang telah ditetapkan oleh AWGS (Gambar).

\section{Hasil}

Pada penelitian ini, 273 orang lansia bersedia mengikuti penelitian. Dari total partisipan, data 229 partisipan yang memenuhi kriteria inklusi dan tidak termasuk eksklusi kemudian dianalisis. Karakteristik partisipan yang terdiri atas usia, berat badan, tinggi badan, indeks massa tubuh, total lemak tubuh, dan massa bebas lemak dapat dilihat pada Tabel 2 .

Pada penelitian ini terdapat partisipan lakilaki $(31,1 \%)$ lebih sedikit bila dibanding dengan

\section{Tabel 2 Karakteristik Partisipan}

\begin{tabular}{lcccccc}
\hline \multirow{2}{*}{ Karakteristik } & \multicolumn{3}{c}{$\begin{array}{c}\text { Laki-laki } \\
\text { (n= 71 orang) }\end{array}$} & \multicolumn{3}{c}{$\begin{array}{c}\text { Perempuan } \\
\text { (n=158 orang) }\end{array}$} \\
\cline { 2 - 7 } & $\begin{array}{c}\text { Rata-rata } \\
\text { (SB) }\end{array}$ & Median & Rentang & $\begin{array}{c}\text { Rata-rata } \\
\text { (SB) }\end{array}$ & Median & Rentang \\
\hline Usia (tahun) & $68,24(6,19)$ & 67 & $60-85$ & $67,20(6,11)$ & 65 & $60-85$ \\
Berat badan (kg) & $63,86(11,2)$ & 65 & $38,6-88,8$ & $58,09(8,94)$ & 57,15 & $36,8-84,7$ \\
Tinggi badan (m) & $1,58(0,08)$ & 1,59 & $1,41-1,74$ & $1,50(0,07)$ & 1,5 & $1,33-1,76$ \\
Indeks massa tubuh (kg) & $25,42(3,91)$ & 25,3 & $15,8-33,2$ & $25,77(4,06)$ & 25,76 & $17,36-40,5$ \\
m²) $_{\text {Total lemak tubuh (\%) }}$ & $28,36(7,99)$ & 26,5 & $5-47,3$ & $37,43(6,70)$ & 38,1 & $19,5-56,4$ \\
Massa bebas lemak (kg) & $43,13(7,26)$ & 44 & $27,6-58,1$ & $34,02(4,03)$ & 33,5 & $20,9-50,5$ \\
\hline
\end{tabular}

Keterangan: SB: simpangan baku 
Tabel 3 Gambaran Indeks Massa Otot, Kekuatan Otot, dan Performa Fisik

\begin{tabular}{|c|c|c|c|c|c|c|}
\hline \multirow{2}{*}{ Karakteristik } & \multicolumn{3}{|c|}{$\begin{array}{c}\text { Laki-laki } \\
\text { (n= } 71 \text { orang) }\end{array}$} & \multicolumn{3}{|c|}{$\begin{array}{c}\text { Perempuan } \\
\text { ( } n=158 \text { orang) }\end{array}$} \\
\hline & $\begin{array}{l}\text { Rata-rata } \\
\text { (SB) }\end{array}$ & Median & Rentang & $\begin{array}{l}\text { Rata-rata } \\
\text { (SB) }\end{array}$ & Median & Rentang \\
\hline Indeks massa otot $\left(\mathrm{kg} / \mathrm{m}^{2}\right)$ & $8,37(1,81)$ & 8,21 & $4,57-16,65$ & $7,07(1,16)$ & 6,89 & $4,13-15,3$ \\
\hline Kekuatan otot $(\mathrm{kg})$ & $23,23(7,25)$ & 22 & $8-39$ & $15,85(4,54)$ & 16 & $4-29$ \\
\hline Performa fisik (m/detik) & $0,95(0,36)$ & 0,92 & $0,3-2,93$ & $0,85(0,25)$ & 0,85 & $0,3-2,73$ \\
\hline
\end{tabular}

Keterangan: SB: simpang baku

perempuan $(68,9 \%)$ dengan total lemak tubuh yang lebih rendah serta massa bebas lemak yang lebih besar bila dibanding dengan partisipan perempuan.

Gambaran parameter sarkopenia penelitian yang terdiri atas indeks massa otot, kekuatan otot dan performa fisik dapat dilihat pada Tabel 3. Nilai parameter sarkopenia pada penelitian ini secara rata-rata lebih besar pada partisipan lakilaki bila dibanding dengan partisipan perempuan dengan perbedaan cukup besar pada kekuatan otot. Algoritma penegakan diagnosis selanjutnya didasarkan pada kriteria yang telah ditetapkan oleh AWGS untuk kemudian diaplikasikan nilainilai cut-off berdasarkan dua nilai acuan. Pada penelitian ini didapatkan perbedaan yang cukup besar untuk prevalensi sarkopenia yaitu dengan jumlah 9,1\% dan 40,6\% berdasarkan nilai cut-off yang berbeda untuk parameter masing-masing diagnosis sarkopenia (Tabel 4).

\section{Pembahasan}

Tabel 2 memperlihatkan partisipan mempunyai indeks massa tubuh (IMT) rata-rata dalam kategori WHO untuk dalam rentang kategori preobese, hal ini serupa dengan hasil penelitian Liu dkk. ${ }^{9}$ di populasi Taiwan yang menemukan bahwa IMT rata-rata laki-laki $24,9(3,4) \mathrm{kg} /$ $\mathrm{m}^{2}$ dan wanita $25,3(4,2) \mathrm{kg} / \mathrm{m}^{2}$. Mengacu pada rekomendasi WHO maka rentang IMT tersebut merupakan kategori risiko yang rendah hingga moderat untuk timbul risiko penyakit sehingga memerlukan tindakan antisipatif.

Pada penelitian ini juga ditemukan bahwa usia, berat badan, tinggi badan, dan massa bebas lemak lebih besar pada laki-laki, sementara IMT, total lemak tubuh lebih tinggi ditemukan pada perempuan (Tabel 2). Hal ini menggambarkan bahwa pada perempuan IMT yang lebih besar terjadi karena dominasi lemak tubuh. Menopause yang terjadi pada perempuan dapat mengubah komposisi tubuh dan distribusi lemak sehingga komposisi tubuh bebas lemak perempuan akan menurun dengan peningkatan berat badan, massa lemak, dan deposisi lemak sentral. ${ }^{12}$

Fungsi jaringan otot rangka merupakan salah satu aspek yang memengaruhi kekuatan fisik, stamina, dan keseimbangan tubuh. Massa otot manusia mengalami perubahan secara konstan. Setelah usia sekitar 50 tahun, massa otot akan mengalami penurunan 1-2\% per tahun, sementara kekuatan otot akan mengalami penurunan sebesar 1,5\% pada usia 50-60 tahun serta $3 \%$ setelahnya. Banyak alasan yang diajukan sebagai penyebab kondisi ini. Salah satunya adalah denervasi unit motorik serta konversi

Tabel 4 Prevalensi Sarkopenia berdasarkan Dua Nilai Cut-off Berbeda untuk Parameter Diagnosis Sarkopenia di Komunitas (Community Dwelling)

\begin{tabular}{lcc}
\hline \multicolumn{1}{c}{ Karakteristik } & $\begin{array}{c}\text { Cut-off Point Rekomendasi } \\
\text { AWGS (n) }\end{array}$ & $\begin{array}{c}\text { Cut-off Point Rekomendasi } \\
\text { Populasi Taiwan (n) }\end{array}$ \\
\hline Kekuatan genggam tangan rendah & 20 (L:17, P:3) & 59 (L:26, P:33) \\
Kecepatan berjalan rendah & 6 (L:5. P:4) & $79(\mathrm{~L}: 34, \mathrm{P}: 45)$ \\
Indeks massa otot rendah & 21 (L:17, P:4) & 93 (L:46, P:47) \\
Sarkopenia & 21 (L:17, P:4) & $93(\mathrm{~L}: 46, \mathrm{P}: 47)$ \\
Prevalensi & $9,1 \%(\mathrm{~L}: 7,4 \%, \mathrm{P}: 1,7 \%)$ & $40,6 \%(\mathrm{~L}: 20,1 \%, \mathrm{P}: 20,5 \%)$ \\
\hline
\end{tabular}

Keterangan: L: laki-laki; P: Perempuan 


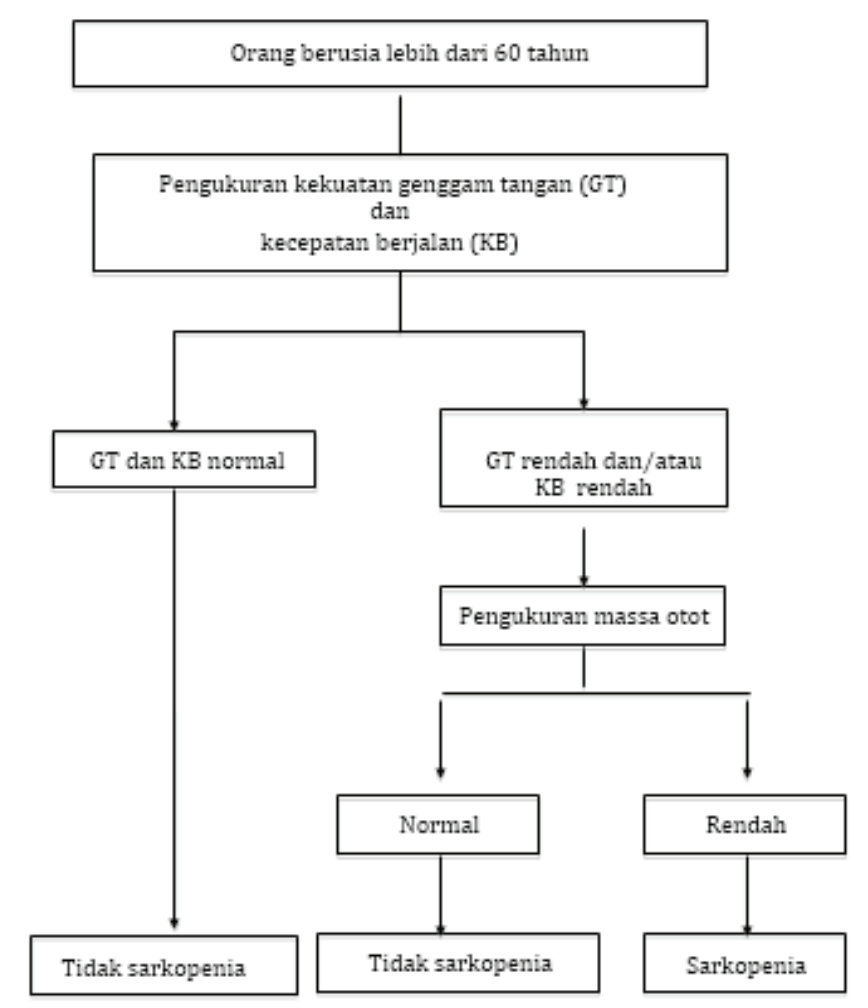

Gambar Alur Penegakan Diagnosis Sarkopenia berdasarkan Rekomendasi AWGS Dikutip dari: Chen dkk. ${ }^{6}$

serabut tipe II yang cepat menjadi serabut tipe I yang lambat sehingga menyebabkan hilangnya daya otot yang penting untuk dapat melakukan aktivitas kehidupan sehari-hari. ${ }^{1,2}$

Indeks massa otot pada laki-laki dalam penelitian ini lebih tinggi bila dibanding dengan perempuan, hal ini serupa dengan penemuan pada populasi Taiwan bahwa laki-laki memiliki indeks massa otot yang lebih besar dibanding dengan perempuan pada kelompok usia 6574 tahun $\left[7,8(0,7) \mathrm{kg} / \mathrm{m}^{2}\right.$ vs $\left[6,6(0,6) \mathrm{kg} / \mathrm{m}^{2}\right]$ yang dapat disebabkan oleh karena perbedaan hormon antara pria dan wanita. ${ }^{9}$

Perhitungan kekuatan genggaman tangan dipertimbangkan sebagai cara pengukuran yang nyaman dan mudah dilakukan dipandang dari sisi biaya, ketersediaan alat dan hubungannya dengan kekuatan kaki. Pada saat ini, kekuatan genggam tangan adalah parameter yang paling sering dipergunakan untuk mengukur kekuatan otot pada penelitian sarkopenia di Asia. AWGS pun merekomendasikan memakai pengukuran kekuatan genggaman tersebut sebagai parameter diagnosis sarkopenia untuk mengukur kekuatan otot. $^{6}$

Determinan utama untuk kekuatan genggam tangan adalah usia, jenis kelamin, total lemak tubuh, dan massa bebas lemak. ${ }^{13}$ Nilai kekuatan genggaman tangan rata-rata pada penelitian ini lebih kecil bila dibanding dengan kekuatan tangan pada penelitian Liu dkk. ${ }^{9}$ pada populasi Taiwan [(laki-laki $23,23(7,25) \mathrm{kg}$ vs $34,4(8,3) \mathrm{kg}$ dan perempuan $15,85(4,54) \mathrm{kg}$ vs $21,2(5,8) \mathrm{kg}]$. Hal ini mungkin disebabkan oleh karakteristik demografi populasi Indonesia (Tabel 2) berusia lebih tua dengan lemak total lemak tubuh yang lebih besar serta massa bebas lemak yang lebih rendah.

Kecepatan jalan lansia rata-rata pada populasi penelitian ini berada pada nilai yang lebih tinggi dari nilai cut-off AWGS, akan tetapi lebih rendah dari nilai cut-off populasi Taiwan (Tabel 1 dan 3). Nilai ini lebih kecil dibanding dengan nilai ratarata yang diperoleh pada populasi Taiwan yang mempunyai rata-rata $1,5(0,5) \mathrm{m} /$ detik untuk laki-laki dan $1,3(0,4) \mathrm{m} /$ detik untuk perempuan karena kemungkinan perbedaan gaya hidup. ${ }^{9}$

Pertimbangan khusus untuk efek kohornya harus diperhatikan lebih lanjut untuk parameter performa fisik dalam diagnosis sarkopenia di Asia karena perubahan gaya hidup sesuai dengan perkembangan jaman yang cenderung terpapar 
pola kebarat-baratan, gaya hidup urbanisasi, perkembangan ekonomik, dan juga transportasi umum. ${ }^{6}$

Prevalensi sarkopenia telah diteliti di negaranegara barat, tetapi hanya beberapa saja yang telah dilaporkan untuk negara Asia. Prevalensi rendah ditemukan di Hong Kong $(12,3 \%$ pada pria dan $7,6 \%$ pada wanita) dan Korea $(6,3 \%$ untuk pria dan $4,1 \%$ untuk wanita ${ }^{14,15}$ Penemuan ini berbeda dengan hasil yang didapatkan pada penelitian yang telah dilakukan di Taiwan yang memberikan hasil prevalensi sarkopenia 18,6\% pada wanita lansia dan $23,6 \%$ pada pria lansia. ${ }^{11}$ Mempergunakan kriteria dari EWGSOP, Yamada $\mathrm{dkk}^{16}$ menemukan prevalensi pria dan wanita berusia 65-89 tahun yang ada di komunitas Jepang adalah $21,8 \%$ dan $22,1 \%$. Prevalensi ini meningkat seiring dengan penambahan usia, terutama pada partisipan yang berusia lebih dari 75 tahun. Kemungkinan seorang lansia menderita sarkopenia menjadi penting untuk diketahui karena kejadian jatuh dan rasa takut jatuh ditemukan lebih tinggi pada penderita sarkopenia apabila dibanding dengan yang tidak sarkopenia. Hal ini mengakibatkan sarkopenia menjadi permasalahan kesehatan di masyarakat yang bermakna mengingat semakin hari jumlah populasi lansia semakin meningkat.

Penelitian ini menemukan rentang angka prevalensi yang berbeda cukup besar untuk sarkopenia dengan mempergunakan dua nilai kriteria nilai cut-off AWGS dan populasi Taiwan (Tabel 4). Terbatasnya populasi lansia yang diteliti hanya mencakup lansia yang tinggal di komunitas (community-dwelling) dan belum dapat memperhitungkan lansia yang tinggal di institusi (institutional-dwelling). Kemungkinan perbedaan karakteristik antropometri dan juga level aktivitas secara umum lansia Indonesia dibanding dengan negara di Asia lainnya serta tidak dipergunakan alat pemeriksaan baku emas di dalam penapisan menjadi limitasi yang memengaruhi hasil penelitian ini.

Simpulan, mengacu pada kriteria AWGS maka prevalensi sarkopenia 9,1\% sementara mengacu terhadap populasi Taiwan ditemukan angka prevalensi sarkopenia 40,6\%. Perbedaan angka prevalensi yang cukup besar memberikan pemahaman bahwa diperlukan penelitian lebih lanjut untuk menentukan nilai cut-off parameter sarkopenia yang spesifik untuk populasi lansia Indonesia di komunitas. Penentuan diagnosis dan penapisan sarkopenia dengan mempergunakan alat yang lebih sensitif dan baku emas, serta penelitian bersifat kohor longitudinal diperlukan agar dapat dilakukan tatalaksana komprehensif termasuk strategi preventif yang tepat untuk kondisi tersebut.

\section{Ucapan Terima Kasih}

Penelitian ini merupakan bagian dari penelitian komunitas yang diadakan oleh Pusat Studi Kebugaran dan Komunitas Fakultas Kedokteran Universitas Padjadjaran (Unpad) Bandung. Kami ucapkan terima kasih atas bantuannya dalam penyelenggaraan penelitian ini pada Prof. Dr. Rully M.A. Roesli, dr., SpPD-KGH, Yulia Sofiatin, dr., Sp.PD, Dwi Eva, dr., Elizabeth Setiawan, dr., dan seluruh mahasiswa yang terlibat.

\section{Daftar Pustaka}

1. Peterson CM, Johannsen DL, Ravussin E. Skeletal muscle mitochondria and aging: a review. J Aging Res. 2012;2012(1):1-20.

2. von Haehling S, Morley J, Anker SD. An overview of sarcopenia: facts and numbers on prevalence and clinical impact. J Cachexia Sarcopenia Muscle. 2010;1(2):129-33.

3. Cruz-Jentoft AJ, Baeyens JP, Bauer JM, Boirie Y, Cederholm T, Landi F, dkk. Sarcopenia: European consensus on definition and diagnosis. Report of the European Working Group on Sarcopenia in Older People. Age Ageing. 2010;39(4):412-23.

4. Thompson DD. Aging and sarcopenia. J Musculoskelet Neuronal Interact. 2007;7(4):344-5.

5. Bijlsma AY, Meskers CG, Ling CH, Narici M, Kurrle SE, Cameron ID, dkk. Defining sarcopenia: the impact of different diagnostic criteria on the prevalence of sarcopenia in a large middle aged cohort. Age. 2013;35(3):871-81.

6. Chen LK, Liu LK, Woo J, Assantachai P, Auyeung TW, Bahyah KS, Chou MY, dkk. Sarcopenia in Asia: consensus report of the Asian Working Group for Sarcopenia. J Am Med Dir Assoc. 2014;15(2):95-101.

7. Setiati S, Istanti R, Andayani R, Kuswardhani RA, Aryana IG, Putu ID, dkk. Cut-off of anthropometry measurement and nutritional status among elderly outpatient in Indonesia: multi-centre study. Acta Med Indones. 2010;42(4):224-30.

8. Teixeira V, Filippim LI, Xavier RM. Mechanisms of muscle wasting in sarcopenia. Rev Bras Reumatol. 2012;52(2):247-59.

9. Liu L, Lee W, Liu C, Chen L, Lin M, Peng L, dkk. 
Age-related skeletal muscle mass loss and physical performance in Taiwan: implications to diagnosic strategy of sarcopenia in Asia. Geriatr Gerontol Int. 2013;13(4):964-71.

10. American Thoracic Society. ATS Statement: guidelines for the six-minute walk test. Am J Respir Crit Care Med. 2002;166(1):111-7.

11. Chien MY, Huang TY, Wu YT. Prevalence of sarcopenia estimated using a bioelectrical impedance analysis prediction equation in community-dwelling elderly people in Taiwan. J Am Geriatr Soc. 2008;56(9):17105.

12. Dehghan M, Merchant AT. Is bioelectrical impedance accurate for use in large epidemiological studies?. Nutr J. 2008;7(1): 26.

13. Ling CHY, de Craen AJM, Slagboom PE,
Westendrop RGJ, Maier AB. Handgrip strength at midlife and familial longevity. Age. 2012;34(5):1261-8.

14. Lau EM, Lynn HS, Woo JW, Kwok TC, Melton LJ. Prevalence of and risk factors for sarcopenia in elderly Chinese men and women. J Gerontol. 2005;60A(2):213-6.

15. Kim TN, Yang SJ, Yoo HJ, Lim KI, Kang HJ, Song W, dkk. Prevalence of sarcopenia and sarcopenic obesity in Korean adults: the Korean sarcopenic obesity study. Int J Obesity. 2009;33(8):885-92.

16. Yamada M, Nishguchi S, Fukutani N, Tanigawa T, Yukutake T, Kayama H, dkk. Prevalence of sarcopenia in community-dwelling Japanese older adults. J Am Med Dir Assoc. 2013;14(12):911-5. 